\title{
Traducciones intra-sistémicas en la literatura infantil y juvenil (1940-1980)
}

\author{
Intra-systemic Translations in Children's Literature \\ (1940-1980)
}

\section{Mónica Domínguez Pérez}

Universitat de Barcelona

Departament de Didàctica de la Llengua i la Literatura

mdomi249@xtec.cat

[recibido 24/09/2014, aceptado 26/01/2015]

\section{RESUMEN}

Partiendo de la teoría de los polisistemas, podemos entender el concepto de traducción intra-sistémica como aquella que es producida, difundida y consumida dentro del mismo polisistema que su texto fuente. En este trabajo se analizarán varios ejemplos de posibles traducciones intra-sistémicas, todos ellos tomados de las literaturas infantiles y juveniles del ámbito español durante el período 1940-1980. Se prestará especial atención a Felipito y sus travesuras, libro traducido del gallego al castellano.

PALABRAS CLAVE: Traducción intra-sistémica, literatura infantil, polisistemas.

\section{RESUMO}

Partindo da teoría dos polisistemas, podemos entender o concepto de tradución intra-sistémica como aquela que é producida, difundida e consumida dentro do mesmo polisistema que o seu texto fonte. Neste traballo analizaranse varios exemplos de posibles traducións intra-sistémicas, todos eles tomados das literaturas infantís e xuvenís do ámbito español durante o período 1940-1980. Prestarase especial atención a Felipito y sus travesuras, libro traducido do galego para o castelán.

PALABRAS CHAVE: Tradución intra-sistémica, literatura infantil, polisistemas.

\begin{abstract}
According to the polysystem theory, intra-systemic translations are those produced, distributed and consumed inside the same polysystem as its source text. In this paper we will analyse several examples of possible intra-systemic translations, all of which belong to children's literature inside the Spanish domain during the period between 1940 and 1980. Special atention will be paid to Felipito y sus travesuras, book translated from Galician to Castilian Spanish.
\end{abstract}

KEY WORDS: Intra-systemic translation, children's literature, polysystem theory.

Domínguez PÉRez, M. (2015): “Traducciones intra-sistémicas en la literatura infantil y juvenil (1940-1980)”, Madrygal (Madr.), 18, Núm. Especial: 183-190.

SUMARIO: 1. Introducción. 2. Obras bilingües. 3. Traducciones a un código lingüístico que carece de polisistema propio. 4. Obras cuyos textos fuente y meta son distribuidos únicamente en el territorio de una literatura periférica. 5. Conclusiones. 6. Referencias bibliográficas. 


\section{INTRODUCCIÓN}

Partiendo de la teoría de los polisistemas y del concepto de traducción intra-sistémica, se investiga a través de este trabajo en las relaciones lingüísticas y literarias en las literaturas del ámbito español (gallega, vasca, catalana y castellana). Se trata de observar qué traducciones podrían ser consideradas intra-sistémicas en la literatura infantil y juvenil de los años 1940-1980, para definir hasta qué punto la lengua constituye una norma de sistema en las literaturas mencionadas, o bien hasta qué punto estas admiten la presencia de obras en diferentes lenguas.

El artículo se apoyará en la teoría de los polisistemas, propuesta por Itamar EvenZohar (1990), ya que ha demostrado ser muy útil para el estudio de las relaciones entre diversas literaturas, especialmente en el ámbito de la traducción. Esta teoría rompe con la tradicional concepción que vincula cada lengua en una nación concreta con una literatura diferente. Por el contrario, un polisistema es considerado una red de relaciones entre todos los elementos vinculados con el concepto de literatura en cada sociedad. De esta forma, en lugar de establecer ideas preconcebidas sobre una determinada literatura nacional (por ejemplo, que tenga que estar escrita en una lengua particular), se debe observar qué relaciones se establecen entre los diferentes elementos: obras, escritores, traductores, lectores, distribuidores, bibliotecas, etc. Desde este punto de vista, la lengua de publicación de un libro no siempre permite establecer de antemano a qué literatura pertenece, sino que hemos de observar dentro de qué red se mueve. Se entiende, por tanto, que un mismo polisistema puede acoger obras en diferentes lenguas.

Surge así el concepto de traducción intrasistémica, que es aquella producida, difundida y consumida dentro del mismo polisistema que su texto original. Por tanto, no siempre pertenecen estas traducciones a la misma literatura nacional que su texto fuente, aunque sí al mismo polisistema, si bien solo podemos afirmarlo con ciertas reticencias.

Por otra parte, según la teoría de los polisistemas todos los elementos que forman una literatura se estructuran en centro (el que lidera las relaciones del polisistema) y periferias, que son sectores más marginales. Si tenemos en cuenta un conjunto de literaturas vinculadas entre sí, como ocurre con las del ámbito español, nos damos cuenta de que también se estructuran en literaturas centrales, más poderosas (en este caso la castellana) y periféricas: la gallega, la vasca y la catalana (Domínguez Pérez 2008). Esta idea es importante porque las relaciones que se establecen entre las diferentes literaturas marcan la producción de traducciones entre ellas.

Vamos a ver algunos ejemplos de traducciones intra-sistémicas tomados de las literaturas infantiles y juveniles del ámbito español durante el período 1940-1980: desde el comienzo de la época franquista hasta la introducción obligatoria de las lenguas vernáculas en la educación básica, hecho que sin duda ha influido en la producción de literatura infantil y juvenil en el ámbito español. Se excluyen de este estudio los cuentos populares de origen extranjero, de modo que podamos entender que todas las traducciones aquí consideradas tienen su origen en el propio ámbito español.

Los ejemplos que se han encontrado se pueden clasificar en tres tipos de traducciones: las obras bilingües, las traducciones a un código lingüístico que carece de polisistema propio y las obras cuyos textos fuente y meta son distribuidos únicamente en el territorio de una literatura periférica.

\section{OBRAS BILINGÜES}

Las obras bilingües no son habituales en la literatura infantil y juvenil del ámbito español, salvo en los comienzos de un nuevo polisistema; por ejemplo, las obras castellanocatalanas de Briz $(1865,1871)$. Desde el sistema de la literatura central, basta con escribir en castellano y publicar en una editorial de ámbito estatal para que el texto sea accesible en todo el territorio del estado español. Desde los polisistemas periféricos, se pretende que los niños aprendan a leer en la lengua nacional, por lo que se les ofrecen textos únicamente en esta lengua. Ocurre así incluso en el polisistema vasco, en que muchas obras 
para adultos se publican en castellano a pesar de sus valores nacionalistas o sus contenidos relacionados con la cultura vasca. Estas son las características de la colección en que se inserta Gabon ipuinak (Cuentos de Navidad) (Estomba 1979), obra bilingüe en euskera y castellano que constituye una excepción dentro de la literatura infantil y juvenil vasca. De hecho, solo tres obras de su misma colección son clasificadas como "Publicaciones infantiles en general. Libros infantiles y juveniles" en la base de datos del ISBN. Probablemente esta adscripción a la literatura infantil y juvenil viene dada por el género cuentístico y la temática navideña, ya que en los paratextos no se hace ninguna referencia, explícita ni implícita, al receptor infantil o juvenil. Se trata, por tanto, de un caso esporádico y discutible, cuyas características no coinciden con el resto de las obras infantiles y juveniles del momento.

Por una parte, la entidad que edita este libro es la Caja de Ahorros Vizcaína, que representa así el único caso en que una empresa de carácter bancario publica una traducción de literatura infantil y juvenil de un texto del ámbito español ${ }^{1}$. Este carácter hace que la iniciativa editorial no posea tanto unos fines lucrativos cuanto culturales, patrióticos y de exaltación de la propia imagen. Esto se refleja en el nombre de la colección, "Temas vizcaínos", y en la explicación de la cubierta posterior:

Para amar a Vizcaya hay que comenzar por conocerla. A esto precisamente van encaminados los afanes de esta iniciativa editorial, pues entendemos que el acrecentamiento de la cultura popular de los vizcaínos es una nueva e importante forma de servir también a Vizcaya, finalidad última de toda nuestra actividad. (Estomba 1979)

"Arte y literatura" es una de las cuatro series de la colección en que se inserta Gabon ipuinak (Cuentos de Navidad). Otro aspecto destacado de este libro con respecto al resto de la literatura infantil y juvenil vasca del momento consiste en el carácter colectivo de los ilustradores, ya que son ocho personas, mencionadas individualmente, pertenecientes a la Asociación Artística Vizcaína. En cambio, se desconoce el autor de la traducción al castellano.

La razón de publicar estos libros en forma bilingüe, a pesar de la valoración positiva sobre el euskera que se desprende de la página preliminar sobre el autor, reside en la escasez de lectores en esta lengua que había, incluso dentro de la Euskalherria, en aquel momento. La prioridad, por tanto, es concedida a la función comunicativa de la traducción: se pretende llegar, gracias al texto castellano, a mayor número de lectores vascos, considerando que aquellos ciudadanos incapaces de leer en euskera pertenecen también a la misma cultura y nación. No se puede descartar que algunos lectores ajenos a la literatura vasca hayan accedido a la obra, como podría ocurrir con cualquier otra, pero la cantidad (sobre todo entre la infancia y la juventud) hubo de ser muy reducida, ya que el libro no se distribuyó sistemáticamente fuera de la Euskalherria. De ahí que, al destinarse texto fuente y texto meta al mismo mercado, consideremos la traducción como intra-sistémica.

Otro tanto se puede decir de Martintxu: Gari-Artoen haziak = Las semillas de trigo y maíz, cuento autoeditado por Txadon (seudónimo de Joseba Euba Zúñiga, 1980). Desconocemos el nombre del traductor, probablemente el propio Euba, y la dirección de la traducción (es decir, cuál fue el primer texto en ser escrito). Ahora bien, esta obra inicia la serie "Martintxu", de carácter bilingüe, que publicará en los años siguientes el Banco de Bilbao. Poniendo en relación estas ediciones con la anteriormente presentada, nos damos cuenta de que solo las entidades bancarias producen libros bilingües, debido a su preocupación más popularista y menos normalizadora de la lengua. En cualquier caso, lo que interesa aquí es resaltar el carácter intra-sistémico de la traducción, más frecuente en otros tipos de textos

\footnotetext{
${ }^{1}$ Sin tener en cuenta las reediciones de Josep Ma Espinàs (1968, 1979 y 1980).
} 
vascos que en la literatura infantil y juvenil. El hecho de que Martintxu sea una autoedición ya muestra que se trata de un caso excepcional. El carácter legendario que posee la serie de Martintxu parece exigir el texto en euskera, con función simbólica de la lengua, mientras que el texto castellano tendría una función fundamentalmente comunicativa.

Se encuentran también en este período cuatro obras trilingües, a juzgar por las referencias bibliográficas. Se trata de los libros que Lechuga autoeditó en Barcelona en 1980. Ha resultado imposible consultar estos libros, por lo que solo disponemos de la indicación bibliográfica de Llibres en català (1980), que nos dicen que están en catalán, castellano y francés. Habría que considerar, pues, la opción de que en lugar de haber traducido todo el texto el autor hubiera utilizado las lenguas para diferentes fragmentos. En este caso no constituirían traducciones. En cuanto a la dirección de la traducción, también es desconocida, aunque al haber sido editados los libros en Barcelona cabe pensar que la lengua de partida pertenece al ámbito español. En todo caso, el desconocimiento que impera sobre estas ediciones impide ofrecer más datos fiables.

\section{TRADUCCIONES A UN CÓDIGO LINGÜÍSTICO QUE CARECE DE PO- LISISTEMA PROPIO}

Entran aquí "traducciones" entre dialectos de una misma lengua, o bien a una variante de otra lengua cuyo mercado y polisistema es compartido con el del texto fuente. En el primer caso se encuentran las eventuales ediciones dobles o múltiples entre los distintos dialectos del euskera, guipuzcoano y vizcaíno, incluyendo a veces también el euskera unificado. Estas traducciones no han podido ser inventariadas de manera exhaustiva por falta de datos suficientes en los catálogos consultados: José M. Torrealdai (1993), por ejemplo, no especifica esta información.
Como traducciones a una variante de otra lengua que carece de polisistema propio se encuentra la colección "Condes populars", traducción aranesa de "Contes populars", de la editorial catalana La Galera. Esta entidad había sido pionera en la producción de las literaturas infantiles y juveniles catalana, gallega y vasca, en estos dos últimos casos a través de la coedición con editoriales de los polisistemas meta. Publicaba ahora dos obras en aranés: Eth doanèr e es cerides (Joles Sennell, seudónimo de Josep Albanell, 1979) y Eth Dragon de Banhòles (Francesc Bofill 1979), con las que tal vez pretendía crear un mercado paralelo, en aranés, que poder liderar. La iniciativa se inserta, por tanto, en la política editorial de La Galera de fomentar las literaturas periféricas del ámbito español, ejerciendo un papel pionero en todas ellas. También se vincula con la reivindicación identitaria y lingüística aranesa que se iniciaba por aquellos años (Viaut 1987: 101).

Como iniciativa editorial, sin embargo, se encuentra aislada, ya que no se registran más libros infantiles en aranés hasta 1984, con nuevas aportaciones de La Galera. La literatura para adultos en aranés tampoco era cultivada durante el período estudiado, por lo que no se puede decir que existiera un proto-sistema ${ }^{2}$ propio. En el Valle de Arán, aunque se hablaba la variante del dialecto gascón del occitano, entre otras lenguas, se leían mayoritariamente los libros en castellano, con alguna incursión en el catalán y en el francés. Las traducciones de "Condes populars", por tanto, pueden ser consideradas intra-sistémicas en la medida en que la literatura catalana era leída también en el Valle de Arán. Se destinaban los "Condes populars" al mismo mercado o circuito literario catalán, aunque restringido a una parte de él. En este sentido se pueden equiparar, salvando la distancia que supone la traducción a una lengua diferente, a los libros destinados a una sola región o provincia.

\footnotetext{
${ }^{2}$ Se habla de proto-sistema cuando el polisistema aún no se ha constituido plenamente, pero constituye ciertas "práticas tendentes à configuraçom dum novo sistema segregado do sistema a que se está vinculado" (Torres 2004: 429).
} 
4. OBRAS CUYOS TEXTOS FUENTE Y META SON DISTRIBUIDOS ÚNICAMENTE EN EL TERRITORIO DE UNA LITERATURA PERIFÉRICA

Tratamos ahora de traducciones cuyos textos de origen y de llegada, aunque publicados en volúmenes separados, funcionan solo para un mismo colectivo de receptores. Aunque los lectores de cada uno de los textos no sean efectivamente los mismos, en principio ambas publicaciones se dirigen a todos ellos y solo a ellos, excluyendo los que se encuentran más allá del territorio más o menos delimitado de la literatura periférica. Las editoriales y los autores pueden ser los mismos, al igual que los locales de comercialización. La diferencia lingüística puede marcar dos caminos distintos en la mediación y recepción, por ejemplo si solo los profesores de la lengua periférica recomiendan la obra a sus alumnos. Sin embargo, las diferencias y límites entre los diferentes polisistemas no están bien marcados. No se puede afirmar que todas las obras de la literatura infantil y juvenil vasca, gallega o catalana estén escritas en sus lenguas nacionales, aunque estas sean, en principio, normas de sistema. Pero tampoco se debe adscribir automáticamente una obra en castellano que solo se distribuye en la Euskalherria al sistema vasco, ya que los modelos repertoriales pueden evidenciar que se inserta en la tradición del polisistema central. Debemos pensar más bien que se trata de obras de frontera, a menudo pensadas desde la perspectiva de la literatura central castellana pero dirigidas a los receptores de una cultura periférica. La aplicación a estos casos del concepto de traducción intrasistémica, en fin, debe ser tomada con cautela y teniendo en cuenta las particularidades de cada caso.
Lo que es evidente es que todas las traducciones de este tipo tienen su texto de origen o el de llegada en castellano, ya que es la única lengua del ámbito español que convive con las periféricas, todas ellas distanciadas territorialmente entre sí. Es, por tanto, la única lengua que podría funcionar en los polisistemas periféricos junto a las lenguas nacionales de estos.

No se ha realizado un estudio detenido en este sentido para las traducciones entre el castellano y el catalán, que podría revelar la presencia de más traducciones intra-sistémicas. No obstante, no parece muy probable que se encuentren muchos ejemplos de traducciones intra-sistémicas de literatura infantil y juvenil entre estas lenguas. El motivo principal es que la mayoría de las editoriales localizadas en Barcelona que publicaban en castellano distribuían sus productos por todo el ámbito español. No ocurría lo mismo, por el contrario, con muchas editoriales vascas y gallegas, cuya distribución se restringía al territorio en que se hablan las lenguas nacionales, aunque sus productos estuvieran en castellano (cosa excepcional en la literatura infantil y juvenil). Encontramos así dos ejemplos de traducciones que podrían considerarse, al menos hasta cierto punto, intra-sistémicas:

Felipito y sus travesuras es una autotraducción del gallego ${ }^{3}$ hecha por la pontevedresa Emilia Estévez (1979), que también autoeditó las dos redacciones de su obra. Colaboraron con ella los tres responsables de las fotografías que complementan el texto. Se trata de una doble edición muy limitada en cuanto a difusión, ya que era la propia autora quien distribuía los ejemplares en librerías y quioscos de Vigo, Baiona y lugares próximos. A pesar del éxito que la autora afirma alcanzar con su obra, y que prueban las reediciones publicadas de cada redacción ${ }^{4}$, hoy en día no se

\footnotetext{
${ }^{3}$ Según han asegurado sus familiares en sucesivas conversaciones telefónicas de mayo de 2006, puesto que en los libros no se encuentra ninguna indicación sobre la dirección de la traducción.

${ }^{4}$ El catálogo del Centro Superior Bibliográfico de Galicia registraba [21 jun. 2006] dos ejemplares de 1979 indicando que se trataba de la segunda edición, pero no era posible consultar los volúmenes. La tercera edición es de 1984 para las dos lenguas. En 1987 la entidad El Paisaje publicó la cuarta edición en castellano.
} 
encuentran ejemplares del texto en castellano en las bibliotecas públicas de fuera ni del interior de Galicia ${ }^{5}$. Del texto fuente se encontraban hasta 2008 ejemplares en seis bibliotecas de la Rede de Bibliotecas de Galicia ${ }^{6}$, sobre todo de la tercera edición. Hoy en día los libros han sido expurgados de las bibliotecas. Cabe pensar, pues, que la distribución fue muy limitada y prácticamente no traspasó las fronteras gallegas. Por tanto, la traducción pudo responder a un intento de alcanzar mayor difusión y prestigio, teniendo en cuenta la diglosia lingüística de la época y la posición central del polisistema castellano. Tal vez por eso la autora no mencionó que se trataba de una traducción.

Aunque los receptores potenciales de esta obra eran los mismos para las dos redacciones $^{7}$, encontramos en este libro elementos ausentes hasta entonces en la literatura infantil y juvenil gallega pero no en la castellana. Lo más innovador son los breves textos insertos en las fotos, que forman fragmentos de un relato paralelo, complementario al texto principal. La historia es la misma, pero contada ahora en la primera persona del yo protagonista. En ocasiones se toman pequeños fragmentos del texto principal (“iSe ahoga!”, Estévez 1979: 30), como era habitual en las novelas juveniles castellanas, por ejemplo en la colección "Juvenil Cadete" de la editorial Mateu. Aunque en el caso que nos ocupa se toman solo las palabras del protagonista y además se imprimen sobre la fotografía y no al pie. Otras veces se crea un fragmento nuevo, con deícticos que señalan lo representado en las fotografías: "Este soy yo" (Estévez 1979: 5). Como hemos indicado, esta manera de crear un relato complementario incrustado en las ilustraciones resultaba innovadora para la literatura infantil y juvenil gallega, y un poco menos para la castellana ${ }^{8}$. También el cuento "Blanca Nieves y los enanitos", mencionado en la página 7 , aún se encontraba ausente en los libros editados en gallego. Sin embargo, era muy popular en la literatura infantil y juvenil castellana y, por tanto, los receptores de la literatura gallega ya lo podían conocer. Algunas de las innovaciones que presenta Felipito y sus travesuras en la literatura infantil y juvenil gallega, por tanto, constituyen transferencias directas (es decir, elementos de otra literatura) introducidas en virtud del carácter bilingüe de la autora y sin necesidad de traducción. De todas formas, la publicación simultánea de los dos textos puede hacer pensar que el texto de origen es el castellano, puesto que el modelo se relaciona más con los repertorios de la literatura infantil y juvenil castellana, de manera que las innovaciones en el sistema gallego se aceptarían como transferencias indirectas (es decir, elementos de otra literatura introducidos a través de la traducción).

Sin embargo, también observamos que en la traducción castellana se omiten algunas alusiones a Ponteareas, el pueblo natal de Emilia Estévez, situado en Galicia: "o día de Corpus, a festa maior do pobo (...) cos anxiños e as da primeira comunión" (Estévez 1979: 13). Este procedimiento delata que Emilia Estévez se dirige a un público más amplio en la traducción, aunque la distribución fuera similar a la del texto fuente.

\footnotetext{
${ }^{5}$ Un ejemplar de 1987 en la Biblioteca de Castilla y León es el único que se encuentra en los catálogos accesibles desde Travesía. En la Rede de Bibliotecas de Galicia y en las bibliotecas asociadas al Proxecto Meiga solo se encuentra un ejemplar en la Biblioteca Pública Municipal de O Rosal (consulta: 17/09/2014).

${ }^{6}$ En la Biblioteca Pública del Estado de Ourense, en la Axencia L.M. en Mañón, en el Centro Superior Bibliográfico y en las municipales de Boiro, Pobra do Caramiñal y Brión (Rede de Bibliotecas de Galicia).

${ }^{7}$ Es probable que la traducción castellana la compraran turistas no gallegos al mismo tiempo que adquirían las guías histórico-turísticas de la autora, pero carecemos de estos datos que en cualquier caso podemos suponer de alcance limitado.

${ }^{8}$ Aunque en forma de bocadillos, los textos inscritos en las ilustraciones que crean un relato complementario ya se encontraban por ejemplo en la "Primera Biblioteca Altea", publicada en castellano en 1974 y traducida al gallego en 1979.
} 
Todos estos aspectos nos hacen creer que la obra fue pensada desde la tradición de la literatura central, aunque se escribiera en primer lugar el texto en gallego. El carácter intra-sistémico de esta traducción, por tanto, es solo una visión parcial de una realidad más compleja.

El último caso de posibles traducciones intra-sistémicas se encuentra en "Ikusi makusi" / "Veo, Veo", una colección que Lur (Hordago) publicó en doble edición en euskera y castellano, pero solo distribuía en la Euskalherria. Aunque muchas de estas obras recogen cuentos clásicos, otras parecen ser textos de origen en lengua vasca. La colección se creó como método de enseñanza del euskera, acompañada de una guía pedagógica e incluyendo en los libros páginas en blanco y negro destinadas a ser pintadas por los niños. El texto, por tanto, tenía una finalidad educativa primordial. En cambio, la traducción castellana fue un añadido pensado por la editorial con motivaciones exclusivamente económicas, a fin de ampliar el número de ventas incluso dentro del mismo marco territorial ${ }^{9}$. La traducción, pues, puede considerarse intra-sistémica, en tanto que tiene su origen en el polisistema vasco (muy vinculado con el sistema educativo) y se destina al mismo colectivo de receptores que su texto fuente. Posteriormente, desde 2001 Erein reedita la colección con el nombre de "Behin batean", pero solo en euskera, puesto que ya el mercado vasco se ha ampliado considerablemente y el texto castellano no es necesario para rentabilizar la edición.

\section{CONCLUSIONES}

En este trabajo se han presentado tres tipos de traducciones que pueden ser consideradas intra-sistémicas. De todas formas, se ha visto que son muy pocas las traducciones de literatura infantil y juvenil de 1940 a 1980 que se podrían denominar, y no de manera categórica, intra-sistémicas. Esto es así porque en las culturas periféricas del ámbito español se pretende hacer de la lengua nacional una norma de sistema, a fin de conformar un polisistema periférico propio fácilmente diferenciable del central. Podemos afirmar, por tanto, que las planificaciones nacionales tienen su reflejo en la realidad de los polisistemas literarios, si bien no logran imponer totalmente el criterio lingüístico.

Recordemos también que muchas de las traducciones intra-sistémicas presentadas resultan de difícil adscripción a un polisistema u otro, constituyendo, por tanto, fenómenos de frontera y poniendo de manifiesto que los polisistemas no están claramente diferenciados de otros polisistemas adyacentes.

\section{REFERENCIAS BIBLIOGRÁFICAS}

Agencia Española Del ISBN: Base de datos de libros editados en España. Madrid: Ministerio de Cultura (http://www.mcu.es/comun/bases/isbn/ISBN.html) [Consulta: 19/11/2009].

BofiLl Surís, Francesc (adap., ilustr.) y Frederic Vergès (trad.) (1979): Eth Dragon de Banhòles. Barcelona: La Galera (colección "Condes populars") [Traducción de: El drac de Banyoles].

BRIz, Francesc P. (1865): Lo llibre dels àngels. Barcelona: Estanislao Roca.

(1871): Lo Llibre dels noys: aplech de rondalles en vers endressat als noys que van a estudi $=$ El Libro de los niños: colección de cuentos en verso dedicado a los niños de corta edad. Barcelona: Estampa de lo Porvenir A.C. de J. Medina.

Centro Superior Bibliográfico de Galicia: Proxecto Meiga. Santiago de Compostela (http:// www.opacmeiga.rbgalicia.org/Portada.aspx) [Consulta: 16/05/2006].

\footnotetext{
${ }^{9}$ Estas declaraciones fueron realizadas por Iñaki Mugica, de la editorial Lur (Hordago) en conversación telefónica del 06/03/2006.
} 
Domínguez PÉRez, Mónica (2008): Las traducciones de literatura infantil y juvenil en el interior de la comunidad interliteraria especifica española (1940-1980). Santiago de Compostela: Universidade [Edición en CD-Rom].

EsPinÀs, Josep Ma , Eulàlia SARIOla i MAYol (ilust.) y Aurora Jorquera (trad.) (1968): Todos tenemos hermanos pequeños. Barcelona: La Galera (colección "Despliega velas") [2 $2^{\mathrm{a}}$ ed. Barcelona: Caixa d'Estalvis i Mont de Pietat de Barcelona, 1979; $3^{\mathrm{a}}$ ed. Barcelona: Caixa de Pensions "la Caixa", 1980].

Estévez Villaverde, Emilia (aut. y trad.); Luis Merino Zoilo, Juan Sixto López, Jesús Urbano Fernández (fotogr.) (1979): Felipito y sus travesuras. Pontevedra: autoedición [Traducción de: As travesuras de Felipiño; $3^{\mathrm{a}}$ ed. 1984; $4^{\mathrm{a}}$ ed. Aranguren (Vizcaya): El Paisaje, 1987].

Estomba Arruabarrena, José Manuel; Antón Uriarte et al. (ilust.) (1979): Gabon ipuinak (Cuentos de Navidad). Bilbao: Caja de Ahorros Vizcaína, Asociación Artística Vizcaína (colección "Temas vizcaínos") [Edición bilingüe].

Euba ZúÑIGA, Joseba (Txadon), Villa y Libarona (ilust.) (1980): Martintxu: Gari-Artoen haziak = Las semillas de trigo y maíz. Galdácano (Vizcaya): autoedición ${ }^{10}$ (colección "Martintxo") [Edición bilingüe].

Even-Zohar, Itamar (1990): Polysystem Studies, en Poetics Today. International Journal for Theory and Analysis of Literature and Communication 11/1. Tel Aviv: Porter Institute for Poetics and Semiotics.

Generalitat de Catalunya (1980): Llibres en català. Barcelona: Departament de Cultura de la, Servei del Llibre / Associació d'Editors en Llengua Catalana (1967-1988).

Ministerio De Cultura: Travesía. Madrid: Ministerio de Cultura, "Bibliotecas y catálogos" (http://travesia.mcu.es/portulano.asp) [Consulta: 07/04/2006].

Rede de Bibliotecas de Galicia: Catálogo colectivo. Santiago de Compostela: Xunta de Galicia (http://catalogo.rbgalicia.org/search*gag S31) [Consulta: 10/11/2006].

Sennell, Joles (adap.), Montserrat Brucart (ilust.) y Frederic Vergès (trad.) (1979): Eth doanèr e es cerides. Barcelona: La Galera (colección "Condes populars") [Traducción de: El burot $i$ les cireres].

TorreAldaI, Joan M. (1993): XX. Mendeko euskal liburuen katalogoa (1900-1992). Bilbao / San Sebastián: Gipuzkoako Foru Aldundia, Kultura eta Turismo Departamentua.

TORREs, Elías (2004): “Contributos sobre o objecto de estudo e metodologia sistémica. Sistemas literários e literaturas nacionais", en A. Abuín González, A. Tarrío Valera (eds.), Bases metodolóxicas para unha historia comparada das literaturas na Península Ibérica. Santiago de Compostela: Universidade de Santiago de Compostela, Servizo de Publicacións e Intercambio Científico, pp. 423-444.

VIAUt, Alain (1987): L'Occitan Gascon en Catalogne espagnole: le Val d'Aran. Burdeos: Maison des Sciences de l'Homme d'Aquitaine.

\footnotetext{
${ }^{10}$ Según la base de datos del ISBN. Sin embargo, el Sistema Nacional de Bibliotecas de Euskadi atribuye la edición al Banco de Bilbao.
} 